\title{
SNMMI Clinical Trials Network Research Series for Technologists: Ethical Issues and Regulations in the Medical Workplace
}

\author{
Sarah Frye ${ }^{1}$, Regan Butterfield ${ }^{2}$, and John M. Hoffman ${ }^{3}$ \\ ${ }^{1}$ Department of Clinical Health Sciences, St. Louis University, St. Louis, Missouri, ${ }^{2}$ Center for Quantitative Cancer Imaging, Huntsman \\ Cancer Institute, University of Utah, Salt Lake City, Utah; and ${ }^{3}$ Huntsman Cancer Institute, University of Utah School of Medicine, Salt \\ Lake City, Utah
}

CE credit: For CE credit, you can access the test for this article, as well as additional JNMT CE tests, online at https://www.snmmilearningcenter.org. Complete the test online no later than December 2024. Your online test will be scored immediately. You may make 3 attempts to pass the test and must answer $80 \%$ of the questions correctly to receive $1.0 \mathrm{CEH}$ (Continuing Education Hour) credit. SNMMI members will have their CEH credit added to their VOICE transcript automatically; nonmembers will be able to print out a CE certificate upon successfully completing the test. The online test is free to SNMMI members; nonmembers must pay $\$ 15.00$ by credit card when logging onto the website to take the test.

\begin{abstract}
Ethical principles and laws have developed as medical practice and research have grown. This article discusses regulatory policies in patient care and the governing bodies that provide oversight. These include but are not limited to the Food and Drug Administration, Office for Human Research Protection, Code of Federal Regulations, Nuclear Regulatory Commission, Joint Commission, Health Insurance Portability and Accountability Act, Occupational Safety and Health Administration, World Health Organization, and International Conference on Harmonization. This article reviews ethical requirements in clinical research and provides examples of medical mistreatment that forced the development of these rules and regulations. Some include the Nuremberg Code, Declaration of Helsinki, and Belmont Report; good clinical practice; and the Common Rule. Several specific research documents are discussed further in this continuing education series. These guiding documents and principles are important because every patient and research subject deserves a safe environment with safe products and protection of privacy. Individuals deserve to understand their role in medicine and clinical research, have the right to refuse care, make informed decisions, know the risks and benefits included, and ultimately have their individual choices respected.
\end{abstract}

Key Words: ethics; ethical regulation; clinical research; informed consent

J Nucl Med Technol 2021; 49:303-310

DOI: $10.2967 /$ jnmt.121.263100

$\mathbf{M}$ edical professionals follow their own principles, which develop from a combination of values, personality, education, upbringing, and the philosophy of where and sometimes when those professionals work. Ethics derives

\footnotetext{
Received Aug. 28, 2021; revision accepted Sep. 21, 2021.

For correspondence or reprints, contact Sarah Frye (sarah.frye@health.slu. edu).

COPYRIGHT (C) 2021 by the Society of Nuclear Medicine and Molecular Imaging.
}

from the Greek word ethos, meaning custom or character, and is defined as "the discipline dealing with what is good and bad and with moral duty and obligation" (1). Ethics is not the same as morality. Morality must specify which codes from a society or group count as moral (2). In another sense, morality refers to a code of conduct that would be accepted by anyone who meets certain intellectual conditions, almost always including the condition of being rational (2). Morality frequently relates to upbringing, culture, personality, and other factors. Ethics brings an added layer to morality that is more systematic (2). Ethics is the systematic study of values by which the determination of what is right and wrong is made (2).

Many individuals would not be where they are today without a strong opinion of right and wrong. How is this professional code established? How do we abide by similar ethical codes for our patients? Why are these rules and regulations in place in patient care? There are enforceable laws followed in our workplace, with regulations coming from governing and regulating bodies. This article summarizes the most prominent in the United States, as well as how each evolved, and discusses additional requirements for individuals involved in research studies. Many principles followed today were developed because of medical experiments and atrocities performed on unknowing participants in the past. Some of these codes and guidelines include the Nuremberg Code, the Declaration of Helsinki, and the Belmont Report. This article reviews the basics of these, how each evolved, how they are applied, and the historical context for their creation. Further articles in this research series will elaborate on these topics.

\section{REGULATORY AGENCIES}

This section discusses the agencies involved in the formation and execution of clinical patient regulations, with a 


\begin{tabular}{ll}
\hline Name & Responsibilities \\
\hline U.S. FDA & $\begin{array}{c}\text { Protects public health by ensuring safety, efficacy, and security of human and veterinary } \\
\text { drugs, biologic products, and medical devices }\end{array}$ \\
\hline CFR & $\begin{array}{c}\text { Organizes rules published by U.S. federal government departments and agencies; is divided } \\
\text { into } 50 \text { titles }\end{array}$ \\
NRC & Ensures safe use of radioactive materials \\
Joint Commission & Sets standards and accredits health-care organizations in United States \\
HIPAA & Provides data privacy and security for safeguarding medical information \\
OSHA & Sets and enforces workplace safety \\
OHRP & Protects human subjects and provides leadership in biomedical and behavioral research \\
WHO & Promotes healthy lives and well-being for all people \\
ICH & Promotes public health safety through international harmonization \\
\hline
\end{tabular}

focus on those most applicable in the United States (Table 1).

\section{U.S. Food and Drug Administration (FDA)}

The U.S. FDA is responsible for protecting public health by ensuring the safety, efficacy, and security of human and veterinary drugs, biologic products, and medical devices (3). The FDA is responsible for protecting public health by ensuring that foods are safe, wholesome, sanitary, and properly labeled and that human and veterinary drugs, vaccines, and other biologic products and medical devices intended for human use are safe and effective (3). The FDA is also responsible for protecting the public from electronic product radiation, ensuring that cosmetics and dietary supplements are safe and properly labeled, regulating tobacco products, and advancing public health by helping to speed product innovations (3).

The FDA can trace its origins back to the creation of the agricultural division in the patent office in 1848. Its origins as a federal consumer protection agency began with the 1906 Pure Food and Drugs Act (4). Not all products undergo review of safety and effectiveness by FDA experts or receive agency approval before being marketed (5). In some cases, the FDA's enforcement efforts focus on products after they are already for sale (5). When FDA approval is not required before a product is sold, the agency has regulatory authority to act when safety issues arise (5).

\section{The U.S. Code of Federal Regulations (CFR)}

The CFR annual edition is the codification of the general and permanent rules published in the Federal Register by the U.S. federal government (6). It is divided into 50 titles that represent broad areas subject to federal regulations (6). Each title is divided into chapters, and each chapter is subdivided into parts or subparts that cover regulatory areas (6). Various parts of the CFR are important to imaging technologists. For technologists who participate in research studies with human subjects, title 21 , part 312 , governs the use of investigational materials, whereas part 50 provides regulations for protections of human subjects via the role of the institutional review board and part 361.1 includes information on radioactive drugs for certain research uses and includes how to report research use of radioactive drugs (7). Title 45, part 164, includes HIPAA requirements. Title 10, parts 19,20 , and $30-37$, have to do with worker safety, radiation protection, and byproduct material (8).

Before the Federal Register Act was established in 1935, the U.S. executive branch agencies and the office of the president would each publish its own regulations in separate publications (8). This excessive number of authoritative documents made it difficult to determine where a U.S. regulation was found, when it was issued, and whether it had been altered or revoked (8). Congress passed the Federal Register Act in 1935, which empowered the archivist of the United States to establish a division within the National Archives to be responsible for the publication of a daily Federal Register (8). This act required that the Federal Register, begun on March 14, 1936, be the federal government's comprehensive documentation for publishing all agency rules, regulations, and executive orders (8).

\section{The U.S. Nuclear Regulatory Commission (NRC)}

The U.S. NRC was created as an independent agency by Congress in 1974 to ensure the safe use of radioactive materials for beneficial civilian purposes while protecting people and the environment (9). The NRC regulates commercial nuclear power plants and other uses of nuclear materials, including nuclear medicine, through licensing, inspection, and enforcement of its requirements (9). Before the NRC was created, nuclear regulation was the responsibility of the Atomic Energy Commission (AEC), which Congress established in the Atomic Energy Act of 1946 (10). Congress later replaced the Atomic Energy Act of 1946 with the Atomic Energy Act of 1954, which made the development of commercial nuclear power possible (10). The AEC functioned by encouraging the use of nuclear power and regulating its safety (10). The AEC's regulatory programs ensured protection of public health from the hazards of nuclear power without imposing excessive requirements that would inhibit the growth of the industry (10). By 1974, 
the AEC's regulatory programs had come under attack, so Congress decided to abolish the agency (10). The Energy Reorganization Act of 1974 created the Nuclear Regulatory Commission, which began in January 1975 (10).

The NRC regulates all persons and organizations that receive an NRC license to use nuclear materials or operate nuclear facilities (11). Today, the NRC's regulatory activities are focused on reactor safety oversight and reactor license renewal of existing plants, materials safety oversight and materials licensing, and waste management of highlevel waste and low-level waste (10). The NRC (like the AEC before it) focuses on several broad radiation issues that are essential to protecting public safety. There are 39 agreement states in the United States as of August 2021 (12). Agreement states have entered NRC agreements that give them authority to license and inspect byproduct, source, or special nuclear materials used or possessed within their borders (12). Agreement state regulations must be as strict as NRC regulations.

\section{The Joint Commission}

The Joint Commission is an independent, not-for-profit organization that seeks to "improve health care for the public, in collaboration with other stakeholders, by evaluating health care organizations and inspiring them to excel in providing safe and effective care of the highest quality and value" (13). Founded in 1951, The Joint Commission accredits more than 22,000 U.S. health-care organizations and programs (13). It is the United States' oldest and largest standards-setting and accrediting body in health care (13). To earn and maintain The Gold Seal of Approval from The Joint Commission, an organization must undergo an on-site survey at least every $3 \mathrm{y}$, with laboratories surveyed every 2 y (13). The Joint Commission's vision is that all people always experience the safest, highest-quality, best-value health care (14).

\section{Health Insurance Portability and Accountability Act (HIPAA)}

HIPAA is U.S. legislation that provides data privacy and security provisions for safeguarding medical information (15). This is in title 45 of CFR with the primary purpose of helping people carry their health insurance between companies and streamline the movement of medical records between institutions (16). Title I is "Health Care Access, Portability, and Renewability," which deals with healthcare plans and policies (16). Title II is "Preventing Health Care Fraud and Abuse" and comprises the privacy rule, the transactions-and-code-sets rule, the security rule, unique identifiers or the national provider rule, and the enforcement rule (16). Medical practices can use a specialized electronic medical record for managing individual records in a larger electronic health records system (16). The law has emerged into greater prominence in recent years with the proliferation of health data breaches caused by cyberattacks on health insurers and providers (17).
Although the law itself was passed in 1996, there have been major additions to HIPAA over the past $25 \mathrm{y}$ with the introduction of the privacy rule, security rule, breach notification rule, and omnibus final rule (18). HIPAA is a living document that attempts to change with the times, and serious penalties can ensue from a HIPAA breach (18). The HIPAA privacy rule deals with protected health information, and the HIPAA security rule deals with electronic protected health information. HIPAA is used daily in patient care and helps keep medical information private and secure.

\section{Occupational Safety and Health Administration (OSHA)}

OSHA is part of the U.S. Department of Labor (19). The Occupational Safety and Health Act of 1970 was passed to prevent workers from being killed or seriously harmed at work (19). This act sets and enforces protective workplace safety and health standards (19). OSHA provides information, training, and assistance to employers and workers (19). Under the Occupational Safety and Health Act, employers have the responsibility to provide a safe workplace. OSHA standards describe the methods employers are legally required to follow to protect their workers (19). Before OSHA can issue a standard, it must go through an extensive process that includes substantial public engagement, notice, and comment (19). OSHA offers help for employers, with free confidential advice (19). Several programs and services help employers identify and correct job hazards and improve their injury and illness prevention programs (19).

Workplaces and employees in the United States must comply with OSHA standards (19). Examples of OSHA standards include requirements to provide fall protection, prevent exposure to some infectious diseases, ensure the safety of workers who enter confined spaces, put guards on machines, provide safety equipment, and provide training for certain dangerous jobs (19). OSHA inspections are initiated without notice and performed by highly trained compliance officers (19). OSHA and the NRC both have radiation dose limits for radiation workers. Radiation produced by machines is overseen by OSHA. Radiation from radionuclides is overseen by the NRC. OSHA and the NRC have the same yearly whole-body radiation exposure limits for occupational workers. OSHA's goal is to keep a safe work environment in the United States.

\section{Office for Human Research Protections (OHRP)}

OHRP provides leadership in the protection of the rights, welfare, and well-being of human subjects involved in research conducted or supported by the U.S. Department of Health and Human Services (20). OHRP also provides guidance, develops educational programs, and maintains regulatory oversight issues in biomedical and behavioral research (20). OHRP was created in June 2000 to lead the Department of Health and Human Services' efforts to protect human subjects in research and to provide leadership for federal agencies that conduct or support human 
subject research under the Federal Policy for the Protection of Human Subjects, also known as the Common Rule (20). OHRP replaced the Office for Protection from Research Risks, which was created in 1972 and was part of the National Institutes of Health. OHRP has oversight in more than 13,000 institutions in the United States and worldwide that conduct Department of Health and Human Services-supported nonexempt human subject research (20).

\section{The World Health Organization (WHO)}

The WHO was founded in 1948 with a broad mandate to act as a coordinating authority on international health issues (21). Its mission is "attainment by all peoples of the highest possible level of health" (21). The U.S. government has been actively engaged with WHO, providing financial and technical support and participating in its governance structure (21). The WHO's primary concern since January 2020 has been the worldwide response to the COVID-19 global pandemic (21). It supports its mission through activities such as providing technical assistance to countries, setting international health standards, providing guidance on health issues, coordinating and supporting international responses to health emergencies, and advocating for better global health (21). WHO is made up of 194 member states, with an executive board comprising 34 members technically qualified in the health field (21). The WHO is headquartered in Geneva, Switzerland, and has a worldwide network of representatives (21).

The WHO successfully achieved initiatives but faces many challenges. Its objective from 2019 to 2023 is to ensure healthy lives and promote well-being for all (21). The WHO has 3 strategic priorities: helping 1 billion people benefit from universal health coverage, ensuring that 1 billion more people are protected against health emergencies, and helping 1 billion more people enjoy better health and well-being (21) .

\section{The International Council for Harmonization of Technical Requirements for Pharmaceuticals for Human Use (ICH)}

The ICH is unique in coordinating technical drug registration guidelines with the engagement of regulators and industry (22). The purpose is promotion of public health through international harmonization that contributes to prevention of unnecessary duplication of clinical trials, to development and registration of new medicines, and to reduction of unnecessary animal testing (22). The ICH's mission is to achieve greater worldwide harmonization to ensure that safe, effective, and high-quality medicines are developed in a resource-efficient manner (23). Harmonization is achieved through a process of scientific consensus with experts to develop ICH guidelines (23). In 2021, the $\mathrm{ICH}$ Association has continued its harmonization, defined strategic priorities, and identified new topics for harmonization (24).
These regulatory organizations guide interactions with medical practitioners regarding patient care. Adding clinical research to the discussion includes another layer of scrutiny on regulatory and ethical guidance. Historically, medical mistreatment under the guise of clinical research contributed to the change in the culture of health care and caused people to be fearful of interactions with health-care providers.

\section{HISTORICAL EXAMPLES OF MISTREATMENT}

Regulations that govern human subject research have evolved because of errors and faulty research practices, including deliberate exploitation of specific populations (usually based on race, religion, mental status, age, socioeconomic status, or sex). With the evolution of digital medicine and Internet-based technology, these regulations are continually adjusted to protect individuals' rights. The examples of targeted mistreatment of discriminated populations have made individuals and communities skeptical of medical treatment and research.

The various examples listed were performed on individuals unaware of the repercussions of this medical treatment. One notable case of mistreatment occurred between 1932 and 1972, when more than 400 African American men were observed to study the natural course of untreated syphilis (25). The study was originally called the "Tuskegee Study of Untreated Syphilis in the Negro Male" (now referred to as the "U.S. Public Health Service Syphilis Study at Tuskegee") (25). Participants' informed consent was not obtained, and participants were told they were being treated for "bad blood" (24). The study continued even after penicillin became the treatment of choice for syphilis in 1943, and participants were not offered this treatment (25). Another case, which began in 1956 and lasted $14 \mathrm{y}$, included mentally disabled children intentionally injected with hepatitis (26). The study goal was to track development of the viral infection to determine the effectiveness of $\gamma$-globulin injections (26). The researchers of this study justified their deliberate infections and exposures by claiming that the high rate of infection in the institution made it practically inevitable that the children would become infected (26).

In 1962, a physician in Brooklyn injected live cancer cells into 22 elderly cancer patients after being rebuffed by his institution, Sloan-Kettering (27). The goal was to learn whether people who were debilitated by cancer could reject cancer cells (27). Study participants were not informed about the risks and were not informed that the experiment involved injecting live cancer cells (27). Three whistleblowers refused to participate in the experiment and brought attention to the hospital board, which eventually accused the original physician of fraud and unprofessional conduct (27).

Of note to imaging technologists, radiation research was not exempt from examples of medical mistreatment. The Advisory Committee on Human Radiation Experiments appointed by President Clinton published an executive 


\begin{tabular}{ll}
\hline Standard & Description \\
\hline Nuremberg Code & Set of research ethical principles for human experimentation from Nuremberg trials \\
Declaration of Helsinki & $\begin{array}{l}\text { General guiding principles for researchers when working with human subjects } \\
\text { Belmont Report } \\
\text { Basic ethical guidelines on human subject research (respect for persons, beneficence, } \\
\text { and justice) }\end{array}$ \\
$\begin{array}{c}\text { Description of clinical trial design and responsibilities of investigator, sponsor, and } \\
\text { institution }\end{array}$ \\
$\begin{array}{c}\text { Rule for creating uniform regulations across U.S. agencies involved in human subject } \\
\text { research }\end{array}$ \\
\hline CFR, part 46, subpart A)
\end{tabular}

summary that found over 4,000 human radiation experiments sponsored by the U.S. federal government between 1944 and 1974 (28). After the discovery of radiation, the discovery of radiation side effects quickly occurred. Individuals were looking for opportunities to understand more about radiation effects on the body. Researchers wanted to advance medical understanding, but there were physicians who did not appreciate the rights of the individuals included in these studies (28). The advisory committee from the Alliance for Human Research Protection found at least 27 experiments that exposed pregnant or nursing mothers and their babies to radiation in nontherapeutic research between 1944 and 1974 (25). One case in the 1940s included a radiation exposure experiment funded by the U.S. Public Health Service that involved 820 poor pregnant White women who were given radioactive iron in a cocktail drink (29). The women were not informed about the contents of the drink or that they were in an experiment (29). The goal of the radiation portion of the experiment was to study the absorption of iron during pregnancy (29). It was later discovered that a higher number of malignancies occurred among the offspring of those that received this cocktail than among the offspring of a control group of similar size (29).

Another case from the 1940 s included 18 terminally ill patients injected with plutonium. Starting in 1945, doctors working with the Manhattan Project initially injected plutonium into 18 men, women, and children (30). The doctors in this study did not obtain consent, and the injections were not given with therapeutic intent (30). The goal was to study the toxic effects of plutonium on selected groups so that physician-scientists would know how to protect American researchers, soldiers, and citizens exposed to atomic weapons (30). In the 1950s, another research study, conducted by Harvard University and the Massachusetts Institute of Technology, gave developmentally disabled boys radioactive calcium and iron in their breakfast cereal (31). From 1946 to 1956, these boys consumed radioactive food to help the researchers better understand the human digestive process, exposing the boys to the radiation-equivalent of at least 50 chest radiographs (31). Parents were never informed that radioactive elements were involved in the tests (31). In a different experiment that ended in 1971, 88 poor, uneducated, and mostly African American patients with incurable cancers were exposed to heavy doses of experimental full-body irradiation (28). Many subjects died hours after treatment and were not provided palliatives against the side effects of nausea and vomiting because the researchers did not want the drugs to interfere with their data collection (28). These cases show that much of the current understanding of radiation effects was collected at the very high cost of devastating experiments on vulnerable individuals without their knowledge or consent.

\section{ETHICAL CODES}

Table 2 summarizes the ethical codes.

\section{The Nuremberg Code}

The Nuremberg Code is a set of research ethics principles for human experimentation resulting from the Nuremberg trials at the end of the Second World War (32). In August 1947, the International Medical Tribunal in Nuremberg, Germany, delivered its verdict in the trial of 23 doctors and bureaucrats accused of war crimes and crimes against humanity for their roles in cruel and often lethal concentration camp medical experiments (32). The Nazi doctors performed twin experiments, freezing experiments, sterilizations, and epidemic jaundice experiments. As part of the tribunal's judgment, the Nuremberg Code was introduced articulating 10 principles for the conduct of human experiments (32). Among other requirements, the code called for the "voluntary consent" of the human research subject, an assessment of risks and benefits, and assurances of competent investigators (32). There has been debate about the code's authorship, scope, and legal standing; however, the Nuremberg Code was a monumental milestone in the history of medical research ethics used worldwide (32).

The main points to take home from the Nuremberg Code are that voluntary consent is essential, research risks must be minimized and be relative to the anticipated benefits of the research, research must benefit society, poorly designed human subject research is unethical from its inception, research must be based on preclinical studies on animals and knowledge of the condition under study, subjects have the right to end their participation in research, proper planning and measures should be taken to protect the subject, 
and the experiment should be conducted only by scientifically qualified persons (33).

\section{The Declaration of Helsinki}

The Declaration of Helsinki is a document that considers the evolving nature of scientific research. It was developed from 10 principles stated in the Nuremberg Code and further incorporated elements from the 1948 Declaration of Geneva, a statement of the ethical duties of physicians (34). It was adopted by the World Medical Assembly in 1964 and has been revised 7 times, with the most recent being in 2013 (35). The Declaration of Helsinki developed as a statement of ethical principles to provide guidance to physicians and other participants in medical research involving human subjects (34). Medical research involving human subjects includes research on identifiable human material or identifiable data (35). The Declaration of Helsinki includes general guiding principles that are the foundation for the ethical standards, including protecting patient health; not allowing knowledge to trample rights; considering the risks, burdens, and benefits of research; protecting vulnerable populations; following scientific requirements and research protocols; using research ethics committees; maintaining privacy and confidentiality; obtaining informed consent; using placebos; making posttrial provisions; regulating and publishing the research; and not using unproven interventions in clinical practice (34).

The guidelines from the Declaration of Helsinki help inform ethical decisions based on medical research. The purpose is to ensure that the well-being of subjects takes precedence over the interests of science and society (34). Some populations are vulnerable and require special protection. Experimental procedures involving vulnerable populations must be detailed in a protocol and submitted to an ethical review committee. Subjects must be informed volunteers. If they are unable to give consent for themselves, a legally authorized representative must consent on their behalf (34). Informed consent (including the process) must be documented (34). The context of obtaining informed consent is as important as the information typed in the document itself.

\section{The Belmont Report}

"The Belmont Report: Ethical Principles and Guidelines for the Protection of Human Subjects of Research," was written by the National Commission for the Protection of Human Subjects of Biomedical and Behavioral Research (36). The commission, created because of the National Research Act of 1974, was charged with identifying the basic ethical principles that should be included in biomedical and behavioral research involving human subjects and in the development of guidelines to ensure that such research is conducted in accordance with those principles (36). Informed by discussions that spanned almost $4 \mathrm{y}$ and an intensive $4 \mathrm{~d}$ of deliberation in 1976, the commission published, in 1976, what became known as the Belmont Report, which identified basic guidelines that address ethical issues arising from the conduct of human subject research (36). The 3 basic principles of the Belmont Report are respects for persons, beneficence, and justice.

Respect for persons is demonstrated by the informed consent process and in safeguards for vulnerable populations (37). Other important concerns are privacy and confidentiality (37). Beneficence has 2 general characteristics: do no harm and maximize benefit while minimizing risk (37). Beneficence is expressed in the use of good research design, competent investigators, and a favorable risk-to-benefit ratio (37). Justice implies fairness and is displayed in the equitable selection of research subjects, ensuring that no group of people is chosen unfairly on the basis of factors unrelated to the research (37). This equitability means that there must be appropriate inclusion and exclusion criteria and a fair system of recruitment (36). The Belmont Report built the foundation for ethical treatment of human subjects in clinical research and associated laws in the United States (37).

\section{Good Clinical Practice (GCP)}

GCP is a set of quality standards for the design, conduct, recording, and reporting of clinical research trials involving human subjects (37). Published by the ICH as a report entitled "E6(R2): Good Clinical Practice," this document describes the responsibilities of the investigator, sponsor, and institution; what should be included in a clinical trial protocol; how research sites should be monitored; and how the investigational product should be controlled (37). GCP is in alignment with federal regulations for conducting research on human subjects, and research sponsors require that investigators and research staff be trained in GCP and conduct their work in accordance with the quality standards. A detailed discussion of GCP and how it impacts medical imaging research is provided later in this series. GCP includes some of the laws previously discussed, local laws, institutional policy, and study-specific requirements. This is not one document; individuals must interpret what GCP means for their specific study, and these interpretations can differ depending on the individual. The ICH assists with some aspects of GCP; the ICH was structured to provide opportunities for standardization of regulatory GCP initiatives (37). The latest revision of ICH E6, released in 2016, focused on the industry changes related to performing trials with more risk-based approaches and provides some clarification on GCP requirements (37). Members of the ICH have updated this standard into their own GCPs (37).

\section{The Common Rule}

The Common Rule was originally adopted in 1991 and revised in 2017 for 17 U.S. agencies and departments involved in human clinical research (37). The rule, published in title 45 of CFR, part 46, subpart A, and entitled "Federal Policy for the Protection of Human Subjects" (37), serves to create a uniform body of regulations across various U.S. agencies involved in human subject research (37). As with other regulatory and ethical guidelines, the 
Common Rule is based on historical documents (including the Nuremberg Code, the Declaration of Helsinki, and the Belmont Report) and several international bioethics codes (30). Compliance with the Common Rule is a requirement for federal funding of research activities.

The 2017 Common Rule revision included improving the process of documenting informed consent. This improvement included requiring that consent forms for certain federally funded clinical trials be publicly available, requiring review by a single institutional review board for cooperative research for some studies, allowing the use of broad consent for future research for secondary studies on stored identifiable data or identifiable biospecimens, eliminating continuing review for certain minimal-risk research, establishing new exempt categories of research based on risk posed to subjects, and adopting a definition of clinical trial that includes behavioral health-related outcomes. The Common Rule is further reviewed later in this continuing education series. Noncompliance can result in penalties to individuals and institutions and loss of a license to practice.

\section{DISCUSSION}

The ethics, values, and regulations that guide medical practitioners' interactions with individuals and research subjects have evolved as the understanding of individual rights has evolved. Current laws and ethical guidance for patient care and research in the United States came directly from regulatory agencies mentioned in this article. Sadly, numerous changes resulted directly from medical atrocities that occurred on specific groups throughout recent U.S. and world history. Laws and guidelines should and will change as understanding, culture, technology, and systems in health care change. Further articles in this series will highlight GCP, the research regulatory environment, and other details about clinical research in medical imaging.

\section{CONCLUSION}

Technologists and other health-care providers should be familiar with the regulatory agencies' ethical guidelines that govern patient care and research. It is important to respect every patient's safety, autonomy, and privacy and to give all patients an informed understanding of their participation in clinical care and research studies. It is imperative that the reader become familiar with these laws and question those that have moral ambiguity. These guiding documents and principles are vital, as individual patients and those participating in clinical trials deserve a safe environment with safe products and confidentiality. Individuals deserve to understand their role in medicine and clinical research and have the right to refuse care, make informed decisions about their care, know the risks and benefits of proposed procedures or interventions, and have their individual choices respected. Critical lessons from past egregious research practices should guide care so that individuals, especially those from targeted and vulnerable populations, are not subjected to medical mistreatment disguised as health care or legitimate clinical research.

\section{DISCLOSURE}

No potential conflict of interest relevant to this article was reported.

\section{ACKNOWLEDGMENTS}

We thank Amanda Abbott, MS, CNMT, RT(N)(CT), PET, from the SNMMI Clinical Trials Network, for her organization for this paper and the series and her willingness to add information and input. We also thank LisaAnn Trembath, FSNMT, CNMT, MHA, from Avid Radiopharmaceuticals, for her subject matter expertise and input on the CE questions.

\section{REFERENCES}

1. Ethic. Merriam-Webster website. https://www.merriam-webster.com/dictionary/ ethic. Accessed September 27, 2021.

2. The definition of morality. Stanford Encyclopedia of Philosophy website. https:// plato.stanford.edu/entries/morality-definition/. Published April 17, 2002. Revised September 8, 2020. Accessed September 27, 2021.

3. What does FDA regulate? U.S. Food and Drug Administration website. www.fda. gov/about-fda/fda-basics/what-does-fda-regulate. Updated June 24, 2021. Accessed September 27, 2021.

4. When and why was FDA formed?" U.S. Food and Drug Administration website. www.fda.gov/AboutFDA/Transparency/Basics/ucm214403.htm. Updated March 28, 2018. Accessed September 27, 2021.

5. Is it really 'FDA Approved?' U.S. Food and Drug Administration website. www. fda.gov/consumers/consumer-updates/it-really-fda-approved. Updated January 17, 2017. Accessed September 27, 2021.

6. Code of Federal Regulations (CFR), 1996 to present. Govinfo website. https:// www.govinfo.gov/help/cfr\#about/. Updated March 17, 2021. Accessed September $27,2021$.

7. Code of Federal Regulations: title 21-food and drugs. eCFR website. https:// www.ecfr.gov/current/title-21. Updated September 21, 2021. Accessed September $27,2021$.

8. McKinney RJ. A research guide to the Federal Register and the Code of Federal Regulations. Law Librarians' Society of Washington, DC, website. https://www. 1lsdc.org/fr-cfr-research-guide . Published 2002. Updated September 16, 2019. Accessed September 27, 2021.

9. About NRC. United States Nuclear Regulatory Commission website. https://www.nrc. gov/about-nrc.html. Updated November 25, 2020. Accessed September 27, 2021.

10. History. United States Nuclear Regulatory Commission website. https://www.nrc.gov/ about-nrc/history.html. Updated August 18, 2021. Accessed September 27, 2021.

11. NRC regulations title 10, Code of Federal Regulations. United States Nuclear Regulatory Commission website. https:/www.nrc.gov/reading-rm/doc-collections/ cfr/index.html. Updated September 14, 2021. Accessed October 5, 2021.

12. NRC: NMSS - state regulations and legislation. United States Nuclear Regulatory Commission website. https://scp.nrc.gov/rulemaking.html. Updated September 23, 2021. Accessed September 27, 2021.

13. History of The Joint Commission. The Joint Commission website. https://www. jointcommission.org/about-us/facts-about-the-joint-commission/history-of-thejoint-commission/. Accessed July 22, 2021.

14. About The Joint Commission. The Joint Commission website. https://www. jointcommission.org/about-us/. Accessed September 27, 2021.

15. Summary of the HIPAA security rule. U.S. Department of Health and Human Services website. https://www.hhs.gov/hipaa/for-professionals/security/lawsregulations/index.html. Reviewed July 26, 2013. Accessed September 27, 2021.

16. The history of HIPAA \& the consequences of a HIPAA violation. Record Nations website. https://www.recordnations.com/articles/history-hipaa/. Accessed September 27, 2021.

17. Lutkevich B. HIPAA (Health Insurance Portability and Accountability Act). SearchHealthIT website. https://searchhealthit.techtarget.com/definition/HIPAA/. Updated August 2020. Accessed July 22, 2021.

18. HIPAA history. HIPAA Journal website. https://www.hipaajournal.com/hipaahistory/. Accessed September 27, 2021. 
19. At-a-glance: OSHA. Occupational Safety and Health Administration website. https://www.osha.gov/sites/default/files/publications/3439at-a-glance.pdf. Accessed September 27, 2021.

20. About OHRP. U.S. Department of Health and Human Services website. https:// www.hhs.gov/ohrp/about-ohrp/index.html. Reviewed February 12, 2016. Accessed September 27, 2021.

21. The U.S. Government and the World Health Organization. KFF website. https:// www.kff.org/coronavirus-covid-19/fact-sheet/the-u-s-government-and-the-worldhealth-organization/. Published January 25, 2021. Accessed September 27, 2021.

22. Overview of ICH. ICH website. https://admin.ich.org/sites/default/files/2021-06/ OverviewOfICH_2021_0614.pdf Published June 2021. Accessed August 23, 2021.

23. Mission: harmonisation for better health. ICH website. https://www.ich.org/page/ mission/. Accessed September 27, 2021

24. ICH Association: 2021 annual work plan. ICH website. https://admin.ich.org/sites/ default/files/inline-files/ICHAssociation_WorkPlan_2021_Approved_2020_1118. pdf. Published October 6, 2020. Accessed September 27, 2021.

25. The Tuskegee timeline. Centers for Disease Control and Prevention website. https://www.cdc.gov/tuskegee/timeline.htm/. Reviewed April 22, 2021. Accessed September 27, 2021.

26. Pecorino PA. Chapter 7: human experimentation. Queensborough Community College website. https://www.qcc.cuny.edu/socialsciences/ppecorino/medical_ ethics_text/Chapter_7_Human_Experimentation/CONTENTS.htm. Published 2002. Accessed September 27, 2021.

27. 1962: Dr. Chester Southam injected live cancer cells into 22 elderly patients. Alliance for Human Research Protection website. https://ahrp.org/1962-dr-chestersoutham-injected-live-cancer-cells-into-22-elderly-patients-at-jewish-chronic-disea se-hospital-in-brooklyn/. Published December 28, 2014. Accessed September 27, 2021.

28. Pacchioli D. Subjected to science. Penn State University website. https://news.psu. edu/story/141518/1996/03/01/research/subjected-science/. Published March 1, 1996. Accessed September 27, 2021.
29. 1945-1947: Vanderbilt "nutrition study" exposed 820 pregnant women to radioactive iron. Alliance for Human Research Protection website. https://ahrp. org/1945-1947-vanderbilt-university-nutrition-study-exposed-820-pregnantwomen-to-tracer-doses-of-radioactive-iron/. Published December 29, 2014. Accessed September 27, 2021.

30. 1945-1947: eighteen patients were injected with plutonium in AEC experiments. Alliance for Human Research Protection website. https://ahrp.org/1945-1947eighteen-patients-were-injected-with-plutonium-in-aec-experiments/. Published December 29, 2014. Accessed September 27, 2021.

31. Advisory Committee on Human Radiation Experiments: final report. Office of Environment, Health, Safety and Security website. https:/ehss.energy.gov/ohre/ roadmap/achre/report.html. Accessed September 27, 2021.

32. Moreno JD, Schmidt U, Joffe S. The Nuremberg Code 70 years later. JAMA. 2017; 318:795-796. 28817743

33. The Nuremberg code. National Institutes of Health website. https://history.nih. gov/display/history/Nuremberg+Code/. Published 1949. Accessed September 27, 2021.

34. Peters B. What is the Declaration of Helsinki? Verywell Health website. https:// www.verywellhealth.com/declaration-of-helsinki-4846525. Updated October 27, 2020. Accessed September 27, 2021.

35. WMA Declaration of Helsinki: ethical principles for medical research involving human subjects. World Medical Association website. https://www. wma.net/policies-post/wma-declaration-of-helsinki-ethical-principles-for-medicalresearch-involving-human-subjects/. Published July 9, 2018. Accessed September 27, 2021.

36. The Belmont Report. U.S. Department of Health and Human Services website. https://www.hhs.gov/ohrp/regulations-and-policy/belmont-report/index.html. Reviewed March 15, 2016. Accessed September 27, 2021.

37. Sather S. Chapter three: regulations and good clinical practice. In: The CRC's Guide to Coordinating Clinical Research. 4th ed. CenterWatch; 2019: 21-31. 